\title{
American Vacuum Society leadership in electronic materials processing: Past, present, and future
}

\author{
Gerald Lucovskya) \\ Departments of Physics, Electrical and Computer Engineering, and Materials, Science and Engineering, \\ North Carolona State University, Raleigh, North Carolina 27695-8202 \\ Gary Rubloff \\ Department of Materials Science and Engineering, University of Maryland, College Park, Maryland \\ 20742-2115
}

(Received 9 June 2003; accepted 17 June 2003; published 2 September 2003)

\begin{abstract}
This article traces the evolution of electronics materials processing in the American Vacuum Society (AVS) up to the present time, and projects the trajectory of this activity into the future. The format and style of this article benefits from perspective of one of the authors (G.L.), who has been editor-in-chief of the Journal of Vacuum Science and Technology (JVST) for more than 20 years, and who has additionally contributed personally to materials processing research through interactions involving AVS symposia, divisions, and publications in the JVST. Major areas of contributions are identified, and then are correlated with the evolution of the AVS and JVST. As we move into the $21 \mathrm{st}$ century, the foundation laid by a strong presence in electronic materials processing is proving to be the basis for emerging cross-disciplinary AVS activities in the nanoscience and technology advances that will continue to evolve in unanticipated ways in $21 \mathrm{st}$ century and beyond. (C) 2003 American Vacuum Society. [DOI: 10.1116/1.1599866]
\end{abstract}

\section{INTRODUCTION}

This article is written in celebration of the 50th anniversary of the founding of the American Vacuum Society (AVS); it also is anticipates the 40th year celebration of the Journal of Vacuum Science and Technology (JVST) in 2004. This society has played a unique role with respect to advances in fundamental science, applied science, technology, and manufacturing in the development and application of electronic materials. This reflects a diverse membership with an outstanding mix of cross-disciplinary interests and talents. Electronic materials processing has a very special place within the society, because it builds on the distant past when the only divisions in place when the JVST was first published in 1964 were Vacuum Metallurgy and Thin Films. This area of AVS participation also projects into the futures as the AVS is continuing to develop, and builds upon a strong presence in nanoscience and nanotechnology. This projection into the future anticipates electronic device processing on a molecular scale, and as well as the emergence of science and technology in fields as diverse as biosensors, microelectronic mechanical devices (MEMS), and field emission displays.

\section{CHALLENGES AND CONTRIBUTIONS TO ELECTRONIC MATERIALS PROCESSING}

The foray into electronic materials by AVS, accompanied by the formation of the electronic materials and processing division (EMPD), was a sea change for the AVS and surface science communities. It demonstrated a determination of the AVS community to seriously address broad issues of technological relevance and the critical scientific underpinnings,

${ }^{a)}$ Electronic mail: gerry_lucovsky@ncsu.edu and in turn it fostered a generation of such focal points including plasma science, nanomaterials and processing, and extending into manufacturing science. The incorporation of these areas was to a large part responsible for the success of AVS and JVST and, in particular, a strong industrial participation in areas at that embraced a broad spectrum from basic research, applied technology, and extending into areas relevant to manufacturing science and technology as well.

This evolution was driven by fundamental questions, e.g., what electronic or structural interactions at metal/ semiconductor interfaces determine their electrical properties? As such, it addressed the following issues:

(1) The central role of chemical bonding and structure in determining the behavior of surfaces and interfaceschemisorption, etc;

(2) Surface analysis approaches to characterizing the composition, structure, and chemistry of interfaces and thinfilm materials - a strong linkage to the industrial applications of surface science;

(3) Deposition, growth, and etching processes as investigated as dynamic processes of surface/interface modification;

(4) Evolution of experimental tools for structural properties (low-energy electron diffraction, scanning probes) and electronic properties (x-ray photoemission spectroscopy, etc.);

(5) Contacts and Schottky barrier properties that determine electrically properties;

(6) Heterojunction fabrication, band alignment, and consequences for heterojunction devices;

(7) Energetic processes (especially plasma) for modification and acceleration of thin-film processes; 
(8) Relation between processes, the equipment in which they are carried out, and the resulting electronic materials device structures that result;

(9) Integration of surface methods with traditional materials (e.g., transmission electron microscopy) and electrical/ magnetic properties approaches as needed for electronic materials problems;

(10) Key processes for early prototyping [e.g., molecularbeam epitaxy (MBE)] and manufacturing [e.g., chemical vapor deposition (CVD)], particularly as investigated in ultraclean and integrated research platforms which capitalize on surface science;

(11) Surface cleaning and passivation, and the fundamental link between them;

(12) Relation of electronic materials processing to process integration, especially areas like lithography and planarization;

(13) Role of defects, their identification, and mechanisms;

(14) Processes of current interest-e.g., atomic layer deposition, ionized sputtering, wet processes (plating, spin casting, and sol gel); and

(15) Implications of semiconductor process research on other fields-basis for MEMS, advances in scanning probe microscopy, bio, etc.

AVS members through contributions to the JVST, participation in AVS Symposia, and conferences supported by Divisions and Chapters of the AVS, many of which have been published in JVST, have played a significant role in advancing the science and technology of Materials Processing. The listing of a very large number of contributors, and a scholarly and complete documentation of their contributions are clearly beyond the scope of this article. Instead, we will attempt to scope out the general areas where significant and sustained contributions have been made, and where these have provided the vision and stimulus for evolving AVS activities. One effective way of identifying specific AVS contributions in a given area is by searching an appropriate website, e.g., the web of science, for a particular topic and including JVST as the journal of choice, or alternatively by scanning the JVST, either electronically, or in the old fashioned way.

There are several different ways to create a hierarchical perspective, and the pathway we have taken is less than unique, since these areas are not completely orthogonal. The most important aspect of this listing is the breadth of AVS activities, which benefits considerably from the applied science base within the society as well.

The broad areas in which AVS members have made outstanding contributions, documented at AVS symposia, in the JVST, and at AVS sponsored symposia and conferences include: (i) Thin-film deposition, (ii) plasma processing, (iii) lithography, (iv) homo- and heteroepitaxy, (v) interface processing, (vi) semiconductor microelectronics process integration, (vii) micromachining, (viii) nanofabrication, (ix) nanopatterning, and (x) vacuum microelectronics. These major areas of microelectronic processing grew out of the some of the early activities within the society, as in the case of thin- film deposition and plasma processing, and are now leading the AVS into areas of applied science and technology that underpin process science and technology on the one hand, and on the other are the foundation for the AVS to emerge as a leader in manufacturing science as well.

The initial focus in thin-film deposition was in evaporation and sputtering, now both characterized as forms of physical vapor deposition. AVS contributions have broadened considerably, and include in alphabetical order major research in: (i) Atomic layer deposition, (ii) CVD, (iii) electrochemical deposition, (iv) electron-beam deposition, (v) hot wire deposition, (vi) ion beam assisted deposition, (vii) plasma-assisted deposition, (viii) photoassisted deposition, and (ix) pulsed laser assisted deposition.

The second focus area is plasma processing. AVS participation in this area followed from early interests in CVD, and the obvious extension to plasma CVD, and this was further enhanced by AVS symposia that included surface science papers. The complete orthogonality of my catalogue scheme has already been breached, since plasma deposition is an obvious approach to thin-film formation as included herein. Major contributions in plasma processing have been documented in AVS archives in the following areas, again in alphabetical order: (i) plasma-assisted CVD, (ii) plasmaassisted etching, (iii) plasma-assisted ion etching, (iv) plasma-assisted surface modification, (v) remote plasmaassisted oxidation and nitridation, and (vi) remote plasmaassisted CVD. Advances in plasma-assisted processing also have relied on advances in plasma-assisted processing systems, including: (i) electron cyclotron resonance plasmas and (ii) high density plasmas, and well as processing modeling and diagnostics which are mainstream AVS activities.

The revolution in semiconductor microelectronic devices and integrated circuits stimulated AVS activities in the following areas: (i) lithography, (ii) homo- and heteroepitaxy, (iii) interface processing, and (iv) process integration, where the AVS tradition of cross-disciplinary excellence has been maintained. The electronic materials processing areas in lithography include: (i) Deep ultraviolet, electron-beam, ion beam, optical, and x-ray excitation, (ii) imaging systems, (iii) mask fabrication, and (iv) resist processing, as well as two techniques that will be listed under nanopatterning as well; (i) scanning tunneling microscope (STM)-based lithography and (ii) nanoimprinting.

Homo- and heteroepitaxy are important processing technologies in both elemental and compound semiconductor processing, and the AVS has played an important role their development and application to processing technologies. The epitaxial growth techniques include: (i) Atomic layer epitaxy, (ii) metalorganic MBE, (iii) MBE, (iv) liquid phase epitaxy, (v) selective area epitaxial growth, and (vi) vapor phase epitaxy. There has also been interest in the epitaxial growth of dielectrics on elemental and compound semiconductors and this has been addressed at the AVS Symposium, Physics and Chemistry of Semiconductor Interfaces (PCSI), and in the JVST.

As aggressive scaling of advanced semiconductor devices 
TABLE I. (a). Maynard M. Welsh award winners: Precursors.

\begin{tabular}{|c|c|c|}
\hline Recipient & Year & Citation \\
\hline $\begin{array}{l}\text { Gottfried K. } \\
\text { Wehner }\end{array}$ & 1971 & $\begin{array}{l}\text { "For his pioneering work in the field of } \\
\text { sputtering, which has profoundly influenced } \\
\text { many other scientists and engineers." }\end{array}$ \\
\hline $\begin{array}{l}\text { Lawrence A. } \\
\text { Harris }\end{array}$ & 1973 & $\begin{array}{l}\text { "For his pioneering work in the field of Auger } \\
\text { electron spectroscopy."- - "His contribution has } \\
\text { had far-reaching impact on the field of surface } \\
\text { science and related technical activities." }\end{array}$ \\
\hline $\begin{array}{l}\text { Homer D. } \\
\text { Hagstrum }\end{array}$ & 1974 & $\begin{array}{l}\text { "For pioneering contributions to ultrahigh } \\
\text { vacuum studies of solid surfaces, especially } \\
\text { the incorporation into a single vacuum chamber } \\
\text { of multiple experimental measurements on } \\
\text { controlled, individual surfaces." }\end{array}$ \\
\hline $\begin{array}{l}\text { Charles B. } \\
\text { Duke }\end{array}$ & 1977 & $\begin{array}{l}\text { "For far-reaching theoretical contributions to } \\
\text { surface science and solid state physics in the areas } \\
\text { of low-energy electron diffraction, electron tunneling, } \\
\text { and the electronic structure of large } \\
\text { organic molecules." }\end{array}$ \\
\hline $\begin{array}{l}\text { Harrison E. } \\
\text { Farnsworth }\end{array}$ & 1981 & $\begin{array}{l}\text { "For his pioneering studies of the preparation, } \\
\text { structural characterization, and properties of } \\
\text { atomically clean surfaces." }\end{array}$ \\
\hline $\begin{array}{l}\text { William E. } \\
\text { Spicer }\end{array}$ & 1984 & $\begin{array}{l}\text { "For his contributions to the development and } \\
\text { application of photoelectron spectroscopy in the } \\
\text { study of the electronic structure and chemical } \\
\text { properties of solids and their surfaces and interfaces." }\end{array}$ \\
\hline $\begin{array}{l}\text { Peter } \\
\text { Sigmund }\end{array}$ & 1988 & $\begin{array}{l}\text { "For theoretical contributions to the field of physical } \\
\text { sputtering and related phenomena." }\end{array}$ \\
\hline
\end{tabular}

(b). Maynard M. Welsh award winners: Processing achievements.

Recipient Year Citation

Harry H. 1983 "For his contributions to growth of thin

Wieder semiconductor single crystal films, and most importantly, for research leading toward III-V MOS technology."

Jerry M. $\quad 1990$ "For seminal contributions to compound Woodall semiconductor science and technology."

Max G.

Lagally

1991 "For outstanding contributions to the quantitative understanding of defects with respect to ordering and growth of surface structures."

Phaedon 1997 "For his seminal contributions to the understanding Avouris of the chemistry of semiconductor surfaces and for his development of the STM as a tool for probing and inducing surface chemical reactions with atomic scale resolution and control."

David E. 1998 "For novel applications and creative development of Aspnes optical methods and effects for research on thin films, surfaces and interfaces which have significantly advanced the understanding of electronic materials and processes."

John H.

1999 "For his seminal contributions to the atomic-level understanding of thin-film growth, interfacial interactions, and etching."

moves into the regime of nanoscale lateral dimensions, the thickness of constituent layers must decrease proportionally as Si field effect transistors, and this in turn means that the performance and reliability of advanced devices is deter- mined to a greater degree by interface bonding, including intrinsic and extrinsic defect bonding arrangements. As such, AVS activities in electronic materials processing have embraced: (i) metal-semiconductor interfaces, (ii) oxide-, and more generally dielectric-semiconductor interfaces, (iii) semiconductor surface passivation, (iv) silicide and germanide formation and interfaces with metals, semiconductors, and dielectrics, and (v) surface cleaning and preparation.

As the complexity and functional of devices based on $\mathrm{Si}$, $\mathrm{SiC}$, and III-V, and II-VI compound devices have increased, semiconductor microelectronics process integration has become an increasingly important area in which significant AVS contributions have been made. These activities represent a bridge between studies of device processing and their integration into manufacturing, hence in the emergence of a Manufacturing Science community within the AVS. Process integration areas include: (i) Chemical mechanical polishing, (ii) furnace annealing, (iii) ion implantation, (iv) laser annealing, (v) plasma-assisted ion implantation, (vi) rapid thermal annealing, and (vii) rapid thermal CVD,

As the integration of devices, and circuits has becoming increasing more multifunctional, a field of device technology has emerged and is this is micromachining. Micromachining embraces many aspects of conventional semiconductor circuit processing including patterning and etching, and as such has been another natural area of technology in which the AVS has a long history of contributions. Specific areas in micromachining include: (i) bulk micromachining, (ii) electroplating and electoforming, (iii) laser micromachining, and (iv) surface micromachining. Emerging applications are in the areas of microfluidics and micro-optics.

The AVS has played a leadership role in the science and technology of nanostructures and is therefore a major player in the emerging revolution in nanodevices with contributions in nanofabrication and nanopatterning, Significant contributions in the area of nanofabrication include: (i) atomic level manipulation, (ii) self-assembly of quantum dots and wires, and molecules, and (iii) tip fabrication, with applications in biological, chemical, electronic, electrochemical, magnetic, optoelectronic and optical devices and circuits. Areas of AVS participation in nanopatterning include: (i) STM-based lithography and (iii) nanoimprinting.

Finally, the AVS has played a leadership roll in vacuum microelectronics with contributions in the areas of (i) cathode fabrication and processing, (ii) electron emission from wide bandgap semiconductors, and (iii) field emission devices, with important applications in field emission flat panel devices.

\section{ELECTRONIC MATERIALS PROCESSING AND THE AVS INFRASTRUCTURE}

The emergence of the Electronic Materials and Processing Division in 1979 was the inevitable outcome of the birth of the AVS in 1952. The AVS brought together a mix of folks from industry, universities, and government laboratories who 
TABLE II. (a). Gaede-Langmuir award winners: Precursors.

\begin{tabular}{lll}
\hline \hline Recipient & Year & \multicolumn{1}{c}{ Citation } \\
\hline Pierre A. Auger & 1978 & $\begin{array}{l}\text { "For establishing the fundamental principle of Auger } \\
\text { Spectroscopy which has led to the most widely used } \\
\text { surface analysis technique of importance to all aspects } \\
\text { of vacuum science and technology." }\end{array}$ \\
Albert Benninghoven & $\begin{array}{l}\text { "For the development of concepts and instrumentation } \\
\text { in static secondary ion mass spectrometry and the } \\
\text { demonstration of its usefulness in manifold } \\
\text { applications." }\end{array}$ \\
Russell D. Young & $\begin{array}{l}\text { "For his invention of the Topografiner, an instrument } \\
\text { which led to the development of the scanning } \\
\text { tunneling microscope." }\end{array}$ \\
Gerald J. Lapeyre & $\begin{array}{l}\text { "For the outstanding contribution to the development of } \\
\text { photoemission spectroscopy with synchrotron } \\
\text { radiation." }\end{array}$ \\
\hline \hline
\end{tabular}

\section{Recipient}

Rointan F. Bunshah

John R. Arthur, Jr.

Francois M. d'Heurle

Gary W. Rubloff

(b). Gaede-Langmuir award winners: Processing achievements.

Year

Citation

1986

"For his scientific and technical insight, demonstration, and continuing involvement in the worldwide implementation of low-temperature vapor-phase deposition of refractory films."

"For pioneering research in the invention and development of MBE and its application to advanced materials and devices."

"For contributions to the science of electronic materials, in particular the understanding of electromigration and silicide materials."

"For the inventive application of surface science and vacuum technology to the semiconductor industry, and for fostering an effective bridge between AVS research and manufacturing."

TABLE III. (a). Albert Nerken award winners: Precursors.

\begin{tabular}{|c|c|c|}
\hline Recipient & Year & Citation \\
\hline John L. Vossen & 1985 & $\begin{array}{l}\text { "For his insightful contributions into the control of thin } \\
\text { film deposition/etching processes and his application } \\
\text { of these technologies to product development." }\end{array}$ \\
\hline
\end{tabular}

\begin{tabular}{|c|c|c|}
\hline \multicolumn{3}{|c|}{ (b). Albert Nerken award winners: Processing achievements. } \\
\hline Recipient & Year & Citation \\
\hline Harold R. Kaufman & 1991 & $\begin{array}{l}\text { "For the invention of the electron-bombardment broad- } \\
\text { beam ion source, and extending its use in thin-film } \\
\text { applications." }\end{array}$ \\
\hline John F. O’Hanlon & 1993 & $\begin{array}{l}\text { "For outstanding contributions to vacuum technology } \\
\text { and the education of its practitioners and for } \\
\text { significant contributions to a range of semiconductor, } \\
\text { display and microcontamination problems." }\end{array}$ \\
\hline Paul H. Holloway & 1999 & $\begin{array}{l}\text { "For seminal contributions to the science and } \\
\text { technology of surface reactions, particularly } \\
\text { low-temperature and beam-stimulated oxidation, and of } \\
\text { ohmic contacts to compound." }\end{array}$ \\
\hline
\end{tabular}


TABLE IV. (a). John A. Thornton award winners: Precursors.

\begin{tabular}{lll}
\hline \hline Recipient & Year & \multicolumn{1}{c}{ Citation } \\
\hline Eric Kay & 1989 & $\begin{array}{l}\text { "For pioneering contributions to the study of film } \\
\text { growth phenomena in sputtering and plasma } \\
\text { polymerization, including study of microstructure } \\
\text { relationship to film properties." }\end{array}$ \\
\hline \hline Recipient & (b). John A. Thornton winners: Processing achievements. \\
Year & 1991 & \multicolumn{1}{c}{ Citation } \\
\hline Joseph E. Greene & 1993 & $\begin{array}{l}\text { "For outstanding research in the area of thin-film } \\
\text { science with emphasis on the effects of ion } \\
\text { bombardment on the growth and properties of } \\
\text { semiconductor materials." }\end{array}$ \\
John W. Coburn & "For seminal work in the mechanistic aspects of \\
Harold F. Winters & 1997 & $\begin{array}{l}\text { materials processing with glow discharges and ion } \\
\text { beams." } \\
\text { "For his pioneering research on ion beam deposition } \\
\text { and sputtered thin films." }\end{array}$ \\
& &
\end{tabular}

were inherently diverse with respect to their science and technology interests, and inherently interdependent through a mix of basic and fundamental science studies to underpin technology development and eventually commercialization of devices and circuits based on electronic materials. During the formative years of the AVS between 1952 and 1964 when the JVST was first launched, the mix had already proved its worth through the quality of the AVS National Symposia and the pressures to preserve the essence of these symposia in an archival science/technology journal, the JVST. At the time of the founding of the JVST in 1964 there were two divisions in place, Thin Films and Vacuum Metallurgy. Microelectronics had not as yet emerged as a focal point with the AVS, but these divisions, had already brought into the AVS community some of the enabling prerequisites for the emergence of an electronic materials processing focus. This included an emphasis on thin-film preparation by physical vapor deposition, chemical vapor deposition, and sputtering, all of which are currently utilized in semiconductor device processing. The emphasis in these early years was more on engineering aspects of these technology areas, and was not strongly supported by significant scientific underpinnings within the AVS community.

In 1968, the Surface Science Division was formed in spite of some opposition within the AVS that suggested nervously that the AVS might be trespassing on the territory of other scientific societies. In retrospect, the formation of the Surface Science Division was the initiative that changed AVS from an engineering society, to a science and technology society, and the JVST Editor responded aggressively, and the JVST changed accordingly. The proceedings of the 1969 AVS symposium published in the Jan/Feb issue of 1970, the first under Paul Redhead's editorship, included a symposium of the Thin-Film Division, as well the first symposium of the Surface Science Division. Surface science and its eventual spawning of an Applied Surface Division were crucial in building a foundation for electronic materials processing, and the surface and interface characterizations required to elevate processing from a shake and bake level to the perspective it now commands.

With strong support from Paul Redhead, the JVST began to focus more on instrumentation and the accompanying science base, and became the only primary publication vehicle for surface science and the related technology applications. This mix has been a characteristic of the other AVS/JVST lead initiatives that have been instrumental in the eventual formation of the EMPD in 1979. In 1970, there were four divisions in the AVS, which were represented by Associate Editors in JVST: Surface Science, Thin Films, Vacuum Metallurgy, and Vacuum Science and Technology. The 1970's heralded an era of expansion for the AVS and JVST, during which electronic materials and processing emerged as a major AVS/JVST thrust and growth area.

Peter Mark became editor of the JVST in 1974, and brought two important conferences in to the AVS community; PCSI, which referred to Physics and Chemistry of Compound Semiconductors, and the "three beams conference": Electron, Ion, and Photon Beam Conference. Both of these are still published regularly in JVST, with a change of name for PCSI to the Physics and Chemistry of Semiconductors. These conferences highlighted areas such as metalsemiconductor Shottky-barrier contacts, and optical, electron-beam and UV lithography.

Two major steps occurred in the next few years: The Electronic Materials and Processing Division was formed in 1979 with Charlie Duke spearheading the charge, and JVST was split into JVST A and JVST B in 1982 under the leadership of Charlie Duke and Gerry Lucovsky. This marked the beginning of an unprecedented era of growth for the JVST as a leading publication in the areas of electronic materials and electronic materials processing.

As noted above, the ingredients were all there, and the seeds were planted in the early 60's, were nurtured in the mid- and late-70's and finally bore fruit in the 80's and into 
TABLE V. (a). Peter Mark award winners: Precursors.

\begin{tabular}{lll}
\hline \hline Recipient & Year & \multicolumn{1}{c}{ Citation } \\
\hline James Chadi & 1983 & $\begin{array}{l}\text { "For innovative, accurate models and theoretical } \\
\text { techniques applied to surface structure } \\
\text { determinations." }\end{array}$ \\
\hline
\end{tabular}

\begin{tabular}{|c|c|c|}
\hline \multicolumn{3}{|c|}{ (b). Peter Mark award winners: Processing achievements. } \\
\hline Recipient & Year & Citation \\
\hline Richard A. Gottscho & 1986 & $\begin{array}{l}\text { "For his insightful applications of spatially and } \\
\text { temporally resolved spectroscopic techniques to the } \\
\text { diagnostics and modeling of processing plasmas." }\end{array}$ \\
\hline Raymond T. Tung & 1987 & $\begin{array}{l}\text { "For his research on the growth and properties of } \\
\text { epitaxial silicides and for major contributions to the } \\
\text { understanding of metal/semiconductor interfaces." }\end{array}$ \\
\hline Jerry Tersoff & 1988 & $\begin{array}{l}\text { "For innovative approaches to the theoretical } \\
\text { understanding of the electronic structure, properties, } \\
\text { and measurement of surfaces and interfaces." }\end{array}$ \\
\hline Randall M. Feenstra & 1989 & $\begin{array}{l}\text { "For original applications of scanning tunneling } \\
\text { microscopy to the study of atomic scale geometric and } \\
\text { electronic structure of surfaces." }\end{array}$ \\
\hline Stephen M. Rossnagel & 1990 & $\begin{array}{l}\text { "For contributions to understanding and applications of } \\
\text { magnetron and ion beam sputtering." }\end{array}$ \\
\hline Robert J. Hamers & 1993 & $\begin{array}{l}\text { "For outstanding contributions to the development of } \\
\text { scanning tunneling microscopy and spectroscopy as } \\
\text { tools for quantitative analysis of the electronic } \\
\text { properties of surfaces." }\end{array}$ \\
\hline Marjorie Olmstead & 1994 & $\begin{array}{l}\text { "For elucidating the nature of semiconductor surfaces } \\
\text { and the heteroepitaxial growth of insulating materials } \\
\text { on these surfaces." }\end{array}$ \\
\hline Brian S. Swartzentruber & 1997 & $\begin{array}{l}\text { "For pioneering studies of atomic-scale, kinetic, and } \\
\text { thermodynamic aspects of the morphology of } \mathrm{Si} \\
\text { surfaces" }\end{array}$ \\
\hline David G. Cahill & 1998 & $\begin{array}{l}\text { "For his seminal contributions to the atomic level } \\
\text { understanding of thermal conductivity in thin films and } \\
\text { surface roughening/smoothing mechanisms during film } \\
\text { growth and etching." }\end{array}$ \\
\hline Eray S. Aydil & 1999 & $\begin{array}{l}\text { "For pioneering work in the development and } \\
\text { application of optical diagnostic techniques to } \\
\text { understand the chemistry and physics associated with } \\
\text { plasma deposition of dielectric thin films." }\end{array}$ \\
\hline Stacey F. Bent & 2000 & $\begin{array}{l}\text { "For contributions to a fundamental understanding of } \\
\text { the reaction processes underlying semiconductor } \\
\text { growth and functionalization." }\end{array}$ \\
\hline Rachel S. Goldman & 2002 & $\begin{array}{l}\text { "For contributions to the fundamental understanding of } \\
\text { strain relaxation, alloy formation, diffusion, and the } \\
\text { correlations among microstructure, electronic, and } \\
\text { optical properties." }\end{array}$ \\
\hline
\end{tabular}

the 21st century as well. The future of electronic materials processing with the mainstream of the AVS is now ensured for many years to come, and with the emergence of a division for Applied Surface Science in 1985, Nanometer-Scale Science and Technology in 1992, and Magnetic Interfaces and Nanostructures in 1999, and the subtitle of JVST B to Microelectronics and Nanometer Structures-Processing, Measurement, and Phenomena.
The electronic materials processing activities are more than just the EMPD, and this is reflected in joint crossdisciplinary sessions with Thin Films, Plasma Science, and Technology, Surface Science, Applied Science, and Nanomaterials. This diversity, and the evolving infrastructure of the AVS and JVST ensure a home for electronic materials processing and its extensions into nanoprocessing and nanotechnology that will be here in 2052, when the AVS celebrates its 
100th year of existence and the JVST its 88th year of continuous publication as well.

\section{EXCELLENCE AND RECOGNITION IN ELECTRON MATERIALS PROCESSING}

As was noted herein, as the AVS grew from a small and focused society that emphasized the applied aspects of vacuum of vacuum science and technology to the diverse organization it is today, the diversity inherent in this group became the enabling factor for advances in the advances in electronic materials processing that continued to emerge and blend into nano- as well as microelectronic devices. This aspect of electronic materials processing is reflected in the value system of the AVS in recognizing outstanding contributors through the Welsh, Albert Nerken, John Thornton and Peter Mark Awards. In the period up to 1979, these awards recognized in part achievements that were either the precursors to the emergence of electronic materials processing within the AVS, or were the directly related to processing activities. The tables presented next separate these awards into these two categories. Details of contributions can be made by simultaneous search the names of award recipients and the JVST.

As indicated in Tables I(a) and I(b) for the Welsh award winners, ail of the awards made prior to 1990 were enabling with respect to electronic materials processing, while all of the awards made after 1990 recognize excellence, and in the heartland of electronic materials processing, including innovative spectroscopic techniques for in situ monitoring of materials growth and surface processing prior to growth. As indicated in Tables II(a) and II(b) for the Gaede-Langmuir Award Winners, all of the awards in Table II(b) the heartland of electronic materials processing were made after the for- mation of the EMPD, while for awards in Table II(a), those bestowed after 1990 represent enabling techniques that have been applied to both micro- and nanoelectronic materials processing. The first Albert Nerken and John A. Thornton Awards (see Tables IIIa, IIIb, IVa, and IVb, respectively) were in the precursor area, and the remaining awards, after 1990 were in the mainstream of electronic materials processing.

The Peter Mark awards (see Tables Va and Vb) of particular significance since they are to young scientists, and therefore project into the future, and specifically targeted to electronic materials. It is therefore important to note that 12 of the last 16 awards have been given to individuals who were doing excellent research in the area of Electronic Materials Processing. In addition, a significant number of these recipients were also doing research that impacts on nano- as well as microelectronic materials and devices. This ensures AVS leadership as the transition from micro- to nanoelectronics progresses.

\section{SUMMARY}

This article is written to commemorate 50 years of AVS history, and focuses on the contributions made by AVS members in the area of electronic materials processing. The paper has presented this from three difference perspectives: (i) Research areas included in electronic materials and processing, (ii) the JVST, and AVS-sponsored symposia and conferences, and (iii) the AVS award winners. The article projects backward recognizing contributions in areas that represent precursor activities that anticipated the AVS entrance into electron materials processing, as well as current activities, and activities which herald the transition from microelectronics to nanoelectronics. 